ఠ

\title{
nab-Paclitaxel as a potential partner with checkpoint inhibitors in solid tumors
}

REVIEW

This article was published in the following Dove Press journal:

OncoTargets and Therapy

21 December 2016

Number of times this article has been viewed

\section{Hatem H Soliman}

Department of Oncologic Sciences, Moffitt Cancer Center and Research Institute, University of South Florida, Tampa, FL, USA
Correspondence: Hatem H Soliman Department of Oncologic Sciences, Moffitt Cancer Center and Research Institute, University of South Florida, I 2902 Magnolia Drive, Tampa,

FL 33612, USA

$\mathrm{Tel}+\mathrm{I} 8137454933$

Fax +I 8137457287

Email hatem.soliman@moffitt.org

\begin{abstract}
Tumors recognized by the host immune system are associated with better survival. However, the immune system is often suppressed in patients with established tumor burden. Stimulating the immune system to detect and kill tumor cells has been a challenge in cancer therapy for some time. Recently, novel cancer immunotherapies, such as immune checkpoint inhibitors, monoclonal antibodies, and vaccine therapies, have emerged as promising therapeutic approaches for many solid tumors. However, for some tumors, immunotherapy alone has not provided significant benefits, and some may even be fully resistant to immunotherapy. It has been suggested that the immune system may require "priming" before an immunotherapy can elicit an immune response. Although chemotherapies are believed to be immunosuppressive, when given at the right dose and sequence these agents may provide this "priming" effect for the immune system. In addition to direct cytotoxic killing of tumor cells, standard chemotherapeutic agents can elicit immunogenicity through various mechanisms. This review highlights the general immunomodulatory properties of chemotherapy agents. It also provides a rationale for combined therapy with $n a b$-paclitaxel and immune checkpoint inhibitors. Recent clinical trial data with these combination regimens in solid tumors are presented, along with a summary of ongoing trials.
\end{abstract}

Keywords: immunotherapy, chemotherapy, nab-paclitaxel, checkpoint inhibitors, solid tumors

\section{Introduction}

The immune system has the unique ability to specifically detect and rid our body of tumor cells. ${ }^{1,2}$ Some tumor cells have aberrant expression of surface antigens, including expression of non-self-antigens or altered expression of self-antigens. These abnormalities help the immune system distinguish tumor cells from normal cells. ${ }^{1}$ Immune recognition and killing of tumor cells is often initiated with the capture of tumor-cell antigens by antigen-presenting cells, including dendritic cells. ${ }^{3}$ Activated (or antigenloaded) dendritic cells present tumor-specific antigens to $\mathrm{T}$ cells and generate a $\mathrm{T}$-cell response in lymphoid tissues that is specific to the antigen presented. Subsequently, $\mathrm{T}$ cells ( $\mathrm{CD} 8^{+}$cytotoxic $\mathrm{T}$ lymphocytes) infiltrate the tumor microenvironment and kill tumor cells in an antigen-specific manner. Tumor killing promotes more antigen release, and the cycle continues under normal conditions. However, a prolonged presence of cytokines and immune cells within the tumor microenvironment (chronic inflammation) may lead to cytotoxic T-lymphocyte anergy and can promote tumor growth and metastasis. ${ }^{3,4}$

In patients with cancer, the immune system has failed to recognize tumor cells as abnormal or has lost the ability to kill tumor cells. ${ }^{3}$ Many mechanisms exist within tumor cells for evading or escaping immune detection, including the ability to downregulate 
antigen expression, which allows tumors to go undetected; ${ }^{3}$ to upregulate surface ligands that mediate T-cell exhaustion or inhibit T-cell function (eg, lymphocyte-inhibitory receptors, such as PD1 and CTLA4); ${ }^{5,6}$ and to secrete factors that locally block cytotoxicity, suppress T-cell activation, or promote expansion of regulatory $\mathrm{T}$ cells, which dampen the immune response. ${ }^{3,4}$ For example, overexpression of PDL1 on tumor cells can lead to increased PD1-PDL1 interaction, allowing tumor cells to evade host immune response through T-cell suppression and reduction of cytokine production and T-cell proliferation. ${ }^{7}$ Other coinhibitory molecules, including BTLA and VISTA, have also been shown to play suppressive roles in cancer immunity. ${ }^{3}$ Recently, studies showed that the CD73-adenosine pathway regulated tumor proliferation, survival, migration, and invasion. Therefore, blockade of CD73 or adenosine could promote antitumor immunity and may enhance the activity of first-generation immune-checkpoint inhibitors. ${ }^{8}$

In addition, tumor burden can simply overwhelm the effector cells of the immune system. Some tumor microenvironments are characterized by the absence of chemokines and infiltrating $\mathrm{T}$ cells. These tumors may have dense stroma (eg, pancreatic cancer), which prevents immune effectors from gaining entry to the tumor microenvironment. The presence or absence of immune cells within the tumor microenvironment has prognostic significance. In general, tumor microenvironments that have high immune-cell density (ie, T cells, mature dendritic cells $)^{9-12}$ or a $\mathrm{CD}^{+} \mathrm{T}$-cell infiltrate ${ }^{13,14}$ have a better prognosis than tumors with low immune-cell density ${ }^{9,13}$ or an increased presence of regulatory T cells. ${ }^{15-18}$ Chemotherapy remains an important part of the treatment regimen for many solid tumors. In addition to direct cytotoxic effects, immunogenic properties of chemotherapy agents may impact the role of chemotherapy in the treatment of many solid tumors, particularly when combined with immunotherapy agents. This review provides an overview of the immunogenic properties of common chemotherapy agents, and also provides a rationale for combining chemotherapy, particularly nabpaclitaxel-based chemotherapy, with checkpoint inhibitors for the treatment of solid tumors.

\section{Overview of checkpoint inhibitors in the treatment of solid tumors}

Activating the immune system to elicit antitumor immunity was a challenge in cancer treatment until the recent breakthrough of the checkpoint inhibitors (anti-CTLA4, anti-PD1/PDL1), which have emerged as a promising therapeutic approach in many solid tumors (Table 1). The role of checkpoint inhibitors in tumor immunity has been described in detail elsewhere. ${ }^{6,19}$ In brief, CTLA4 is expressed on cytotoxic T cells and is upregulated shortly after T-cell activation. CTLA4 has a high affinity for B7 molecules expressed by dendritic cells. The interaction of B7 molecules with CD28 expressed by T cells is the costimulatory

Table I Checkpoint inhibitors approved for the treatment of solid tumors in the US and Europe

\begin{tabular}{|c|c|c|c|c|c|}
\hline $\begin{array}{l}\text { Checkpoint } \\
\text { agent }\end{array}$ & Target & $\begin{array}{l}\text { Immunoglobulin } \\
\text { subtype }\end{array}$ & Indication & Country & Manufacturer \\
\hline Ipilimumab 22,25 & CTLA4 & $\lg G_{1} \kappa$ & Unresectable/metastatic melanoma & US, Europe & Bristol-Myers Squibb \\
\hline \multirow[t]{3}{*}{ Pembrolizumab ${ }^{23,26}$} & PDI & $\lg _{4} \kappa$ & Unresectable/metastatic melanoma & US, Europe & Merck \\
\hline & & & PDLI-positive metastatic NSCLC & US, ${ }^{a}$ Europe ${ }^{b}$ & \\
\hline & & & Recurrent/metastatic HNSCC ${ }^{\mathrm{c}, \mathrm{d}}$ & US & \\
\hline \multirow[t]{3}{*}{ Nivolumab ${ }^{21,33}$} & PDI & $\lg _{4} \kappa$ & Unresectable/metastatic melanoma & US, ${ }^{e}$ Europe ${ }^{f}$ & Bristol-Myers Squibb \\
\hline & & & Locally advanced/metastatic NSCLC & US,g Europe ${ }^{h}$ & \\
\hline & & & Advanced renal cell carcinoma & US,' Europe & \\
\hline \multirow[t]{3}{*}{ Atezolizumab ${ }^{24}$} & PDLI & $\lg G_{1}$ & Locally advanced/metastatic & US & Hoffmann-La Roche \\
\hline & & & urothelial carcinoma ${ }^{\mathrm{c}, \mathrm{k}}$ & & \\
\hline & & & Metastatic NSCLC ${ }^{g}$ & & \\
\hline
\end{tabular}

Notes: approved for patients with high PDLI expression, no EGFR or ALK mutations, and no prior chemotherapy for metastatic disease. Also approved for patients with PDLI-positive tumors who have progressed on or after platinum-containing therapy, and if EGFR- or ALK-mutation-positive, patients must have disease progression on FDA-approved therapy for those mutations before receiving pembrolizumab. bLocally advanced or metastatic NSCLC. Patients must have received one or more prior chemotherapy regimens, and if EGFR- or ALK-mutation-positive, patients must have received prior treatment with approved therapy for these mutations before receiving pembrolizumab. Indication granted under accelerated approval, and continued approval may be contingent upon verification of clinical benefit. ${ }^{\mathrm{P}}$ Patients must have disease progression on or after platinum-containing therapy. ${ }^{\mathrm{e} A p p r o v e d ~ a s ~ a ~ s i n g l e ~ a g e n t ~ f o r ~ B R A F ~}{ }^{\mathrm{v} 600}$ wild type and under accelerated approval, which may be contingent upon verification of clinical benefit for $B R A F^{v 600}$-mutation-positive melanoma, and for unresectable or metastatic melanoma in combination with ipilimumab. ${ }^{\mathrm{A}} \mathrm{As}$ monotherapy or in combination with ipilimumab. 8Metastatic NSCLC with progression on or after platinum-based chemotherapy; patients with EGFR or ALK mutations must have disease progression on FDA-approved therapy for these aberrations prior to receiving nivolumab or atezolizumab. "Locally advanced or metastatic NSCLC after prior chemotherapy.


or progression within 12 months of neoadjuvant/adjuvant treatment with platinum-containing therapy.

Abbreviations: FDA, US Food and Drug Administration; HNSCC, head and neck squamous cell carcinoma; NSCLC, non-small-cell lung cancer. 
signal for T-cell activation. Therefore, CTLA4 binding of B7 molecules suppresses T-cell activity. CTLA4 antibodies, such as ipilimumab and tremelimumab, block CTLA4 from interacting with B7 molecules and enhance T-cell activation. Similarly, another checkpoint molecule, PD1, is expressed by T cells during long-term antigen exposure and activation. ${ }^{19,20}$ Interaction of PD1 with PDL1, expressed on tumor cells and antigen-presenting cells, dampens the T-cell response by inhibiting T-cell activation and proliferation. Antibodies to PD1 (eg, nivolumab and pembrolizumab) and PDL1 (eg, atezolizumab and durvalumab) prevent the interaction of PD1 with PDL1. Over the span of the last 5 years, several checkpoint inhibitors (eg, ipilimumab, nivolumab, pembrolizumab, atezolizumab, and durvalumab) have gained either an indication or breakthrough-therapy designation in multiple solid tumors (eg, melanoma, lung, renal, head and neck, and bladder) based on positive clinical trial data. ${ }^{21-27}$

In 2011, ipilimumab, a CTLA4-specific monoclonal antibody, was the first checkpoint inhibitor approved in the US and Europe based on a nearly 4-month improvement in survival versus a vaccine therapy in a Phase III trial of patients with metastatic melanoma. ${ }^{22,25,28} \mathrm{~A}$ few years later, pembrolizumab and nivolumab became the first PD1 inhibitors approved for advanced melanoma based on positive clinical trial data. ${ }^{21,23,26,29-33}$ A Phase III trial in advanced melanoma subsequently demonstrated that combined therapy with ipilimumab (3 mg/kg) plus nivolumab ( $1 \mathrm{mg} / \mathrm{kg})$ every 3 weeks ( $\mathrm{q} 3 \mathrm{w}$ ) for four doses followed by nivolumab (3 mg/ $\mathrm{kg}$ ) every 2 weeks ( $\mathrm{q} 2 \mathrm{w}$ ) for cycle 3 and beyond led to longer progression-free survival (PFS) compared with either agent alone (11.5 vs 2.9 months with ipilimumab, hazard ratio [HR] for death or disease progression $0.42 ; P<0.001$ ) and 6.9 months with nivolumab (HR 0.74, $P=\mathrm{NR}$ vs ipilimumab alone).$^{34}$ This combination was recently approved in the US for the first-line treatment of patients with unresectable or metastatic melanoma. In addition to activity in melanoma, PD1 inhibitors have demonstrated activity in a number of other cancers, including lung, ovarian, stomach, and kidney cancers. ${ }^{35-40}$

In 2015, nivolumab was the first immunotherapy approved for the treatment of patients with metastatic non-smallcell lung cancer (NSCLC) and progression during or after platinum-based chemotherapy ${ }^{21,33}$; nivolumab was initially approved for patients with squamous histology, but this approval was closely followed by an approval in patients with nonsquamous histology. These approvals were based on the results of two Phase III trials. ${ }^{35,36}$ In these trials, nivolumab (3 $\mathrm{mg} / \mathrm{kg} \mathrm{q} 2 \mathrm{w}$ ) versus docetaxel reduced the risk of death by $41 \%$ (median overall survival [OS] 9.2 vs 6.0 months, HR $0.59 ; P<0.001)$ in previously treated patients with advanced squamous NSCLC and by $27 \%$ (12.2 vs 9.4 months, HR $0.73 ; P=0.002$ ) in previously treated patients with nonsquamous NSCLC. The incidence of grade 3 or 4 treatment-related adverse events was lower with nivolumab versus docetaxel (7\% vs 55\% in squamous NSCLC, $10 \%$ vs $54 \%$ in nonsquamous NSCLC). Pembrolizumab gained an indication under accelerated approval in the US for the second-line treatment of patients with NSCLC tumors that express PDL1 based on improved tumor response and durability of response; it is now also approved for the treatment of patients with advanced NSCLC and high PDL1 expression with no EGFR/ALK aberrations who have received no prior chemotherapy, as well as patients with metastatic melanoma and patients with recurrent/metastatic squamous cell carcinoma of the head and neck. ${ }^{23,41}$ Recently, atezolizumab, a PDL1 inhibitor, was approved for the treatment of patients with locally advanced or metastatic urothelial carcinoma who have progressed on platinum-based chemotherapy or have disease progression within 12 months of neoadjuvant or adjuvant treatment with platinum-containing chemotherapy, as well as patients with metastatic NSCLC after progression during or after platinumcontaining chemotherapy. ${ }^{24}$ Durvalumab is an investigational PDL1 inhibitor that (although not yet approved) has demonstrated antitumor activity in a number of solid tumors. ${ }^{42}$

\section{Chemotherapy in combination with checkpoint inhibitors}

For many tumors, checkpoint blockade alone has not provided significant benefits, and some, such as pancreatic tumors, appear to be fully resistant to checkpoint inhibitors. ${ }^{43-45}$ It has been suggested that the immune system may require "priming" prior to or in conjunction with an immunotherapy agent. ${ }^{3,46}$ Although numerous chemotherapy agents have known immunosuppressive adverse events, some may possess this "priming" effect to the host immune system, helping to elicit an antitumor T-cell response. ${ }^{46}$ Cytotoxic killing of tumors provides a natural source of cancer-associated antigens. Therefore, combining chemotherapy with a checkpoint inhibitor could create an immunogenic "feedback loop", increasing antigen presentation and immune response. ${ }^{3}$

\section{Immunomodulatory properties of standard chemotherapy}

Chemotherapy has been a mainstay of cancer treatment and will likely remain as such, even with the discovery of 
new targeted therapies and immunotherapies. ${ }^{47}$ In addition to direct cytotoxic killing of tumor cells, standard chemotherapeutic agents can elicit immunogenicity through various mechanisms. ${ }^{3,48,49}$ Immunomodulatory properties of common chemotherapies (eg, cyclophosphamide, antimetabolites, anthracyclines, platinum agents, and taxanes) have been reviewed by Bracci et al. ${ }^{48}$ In brief, many cytotoxic agents have been shown to recruit immune cells (ie, dendritic cells, macrophages, and natural killer cells) to the tumor microenvironment, enhance tumor-cell death by converting dying tumor cells into endogenous vaccines, stimulate natural killer-dependent antitumor immunity and T-cell responses, induce phagocytosis of cell debris by dendritic cells and antigen presentation to T cells, sensitize tumor cells to cytotoxic $\mathrm{T}$ lymphocytes, and disrupt immune suppressor mechanisms by selectively depleting myeloid-derived suppressor cells and suppressing regulatory $\mathrm{T}$ cells. These immunomodulatory properties make chemotherapy agents ideal candidates for combination with immunotherapies.

Although high doses of chemotherapy can be immunosuppressive, chemotherapy agents can enhance the antitumor activity of immunotherapy when given at an optimal dose (ie, low dose) and sequence. ${ }^{50-52}$ In a preclinical mouse model of platinum-resistant relapsed ovarian cancer, a dose-dense regimen of low-dose paclitaxel/carboplatin versus the maximumtolerated-dose regimen was less toxic to the immune system, reduced immunosuppression by components of the tumor microenvironment, and stimulated recruitment of macrophages and $\mathrm{CD} 8^{+} \mathrm{T}$ cells to tumors. ${ }^{53}$ Preclinical evidence also supports giving chemotherapy prior to vaccine immunotherapy and at doses slightly higher than the dose levels that begin to induce cytopenias. ${ }^{51}$ In a clinical study of patients with metastatic breast cancer, low doses of cyclophosphamide/ doxorubicin enhanced the immune response to an allogeneic, HER2-positive, GMCSF-secreting breast-tumor vaccine in patients with breast cancer. ${ }^{54}$ In the same study, higher doses of cyclophosphamide were shown to suppress immunity. Therefore, when given at an optimal dose and sequence, chemotherapy may enhance the immune response rather than suppress it. Striking the right balance will be critical to the further development of effective chemotherapy-immunotherapy combination regimens.

\section{Immunomodulatory properties of taxanes}

Taxanes are widely used chemotherapy agents in the treatment of solid tumors, including breast, lung, and pancreatic cancers, among others. ${ }^{55-57}$ It is well known that taxanes inhibit cell division by stabilizing microtubules, but they can also act as lipopolysaccharide mimetics and can activate macrophages to mediate direct cytotoxicity against tumor cells. ${ }^{58}$ Taxanes may also provide long-term immune benefits, have been shown to increase tumor-infiltrating lymphocytes, ${ }^{59}$ and have demonstrated a positive effect on T-cell proliferation and natural killer-mediated tumor-cell lysis in breast cancer tumors. ${ }^{60} \mathrm{~A}$ greater influx of tumor-infiltrating lymphocytes in breast cancer tumors has been correlated with a better response to chemotherapy. ${ }^{59,61}$ Paclitaxel may be a particularly strong immunostimulant, as it is able to both activate $\mathrm{CD}^{+} \mathrm{T}$ cells and reduce immunosuppressive cells, such as regulatory T cells. ${ }^{62,63}$ Docetaxel has been shown to increase $\mathrm{CD} 8^{+} \mathrm{T}$-cell production of IFN $\gamma$ (a stimulator of tumor-cell killing), but docetaxel does not appear to inhibit the suppressor function of regulatory T cells. ${ }^{64} \mathrm{In}$ a preclinical model, lower-dose taxanes appeared to induce maturation of myeloid-derived suppressor cells into more mature dendritic cells independently of TLR $4 .{ }^{65}$ In patients with advanced breast cancer, treatment with paclitaxel or docetaxel was also associated with enhanced natural killercell activity ${ }^{66}$ In addition, a study showed that the antitumor effects of paclitaxel may be mediated by myeloid-derived suppressor cells. ${ }^{67}$ Taxanes regulate many aspects of immune function, including lymphocyte recruitment and activation and production of immunoenhancing cytokines, including IL-12, IFN $\gamma$, TNF $\alpha$, and GMCSF, all of which may augment the antitumor activity of immunotherapies. ${ }^{58}$ Tumor cellderived TGF $\beta$ has been shown to inhibit paclitaxel-induced macrophage activation; therefore, depletion of TGF $\beta$ may provide a mechanism for restoring the immunomodulatory properties of taxanes. ${ }^{68}$

\section{Taxane-based chemotherapy with immune-checkpoint inhibitors}

The combination of taxanes with checkpoint inhibitors in solid tumors has been supported in early clinical studies (Table 2). However, to date, no clinical trial has reported results for combined therapy with docetaxel plus a checkpoint inhibitor. In a Phase II trial of paclitaxel/carboplatin and ipilimumab $(10 \mathrm{mg} / \mathrm{kg})$ in advanced lung cancer, 204 chemotherapy-naïve patients with NSCLC received (1:1:1) concurrent ipilimumab (four doses of ipilimumab plus paclitaxel/carboplatin followed by two doses of placebo plus paclitaxel/carboplatin), phased ipilimumab (two doses of placebo plus paclitaxel/carboplatin followed by four doses of ipilimumab plus paclitaxel/carboplatin), or a control regimen (up to six doses of placebo plus paclitaxel/carboplatin) ${ }^{69}$ 
Table 2 Conventional paclitaxel in combination with checkpoint inhibitors

\begin{tabular}{|c|c|c|c|c|c|c|c|}
\hline \multirow[t]{2}{*}{ Study } & \multirow[t]{2}{*}{$\mathbf{n}$} & \multirow[t]{2}{*}{ Population } & \multirow[t]{2}{*}{ Treatment } & \multicolumn{3}{|l|}{ Efficacy } & \multirow{2}{*}{$\begin{array}{l}\text { Grade } 3 / 4 \\
\text { AEs }\end{array}$} \\
\hline & & & & ORR & $\begin{array}{l}\text { Median PFS, } \\
\text { months }\end{array}$ & $\begin{array}{l}\text { Median OS, } \\
\text { months }\end{array}$ & \\
\hline $\begin{array}{l}\text { Lynch } \\
\text { et } \mathrm{al}^{69}\end{array}$ & 204 & $\begin{array}{l}\text { First-line, } \\
\text { stage IIIB/IV } \\
\text { or recurrent } \\
\text { NSCLC }\end{array}$ & $\begin{array}{l}\text { A Placebo + Pac } 175 \mathrm{mg} / \mathrm{m}^{2}+ \\
\text { Carbo AUC } 6 \text { q3w } \leq 6 \text { doses } \\
\text { B Concurrent (Ipi } 10 \mathrm{mg} / \mathrm{kg}+ \\
\text { Pac/Carbo q3w } 4 \text { doses } \rightarrow \\
\text { placebo + Pac/Carbo q3w } \\
2 \text { doses) } \\
\text { C Phased (placebo + Pac/Carbo } \\
\text { q3w } 2 \text { doses } \rightarrow 1 \mathrm{lpi} 10 \mathrm{mg} / \mathrm{kg}+ \\
\text { Pac/Carbo q3w } 4 \text { doses) }\end{array}$ & $\begin{array}{l}\text { Best ORR by } \\
\text { irRC } \\
\text { A } 18 \% \\
\text { B } 21 \% \\
\text { C } 32 \%\end{array}$ & $\begin{array}{l}\text { irRC } \\
\text { A } 4.6 \\
\text { B } 5.5 \\
\text { C } 5.7 \\
\text { Modified WHO } \\
\text { A } 4.2 \\
\text { B } 4.1 \\
\text { C } 5.1\end{array}$ & $\begin{array}{l}\text { A } 8.3 \\
\text { B } 9.7 \\
\text { C } 12.2\end{array}$ & $\begin{array}{l}\text { (Immune- } \\
\text { related) } \\
\text { A } 6 \% \\
\text { B } 20 \% \\
\text { C } 15 \%\end{array}$ \\
\hline Reck et al ${ }^{71}$ & 130 & $\begin{array}{l}\text { First-line, } \\
\text { extensive-disease } \\
\text { SCLC }\end{array}$ & $\begin{array}{l}\text { A Placebo + Pac } 175 \mathrm{mg} / \mathrm{m}^{2}+ \\
\text { Carbo AUC } 6 \text { q3w } \leq 6 \text { doses } \\
\text { B Concurrent (Ipi } 10 \mathrm{mg} / \mathrm{kg}+ \\
\text { Pac/Carbo q3w } 4 \text { doses } \rightarrow \\
\text { placebo }+ \text { Pac/Carbo q3w } \\
2 \text { doses) } \\
\text { C Phased (placebo }+ \text { Pac/Carbo } \\
\text { q3w } 2 \text { doses } \rightarrow 1 \mathrm{lpi} 10 \mathrm{mg} / \mathrm{kg}+ \\
\text { Pac/Carbo q3w } 4 \text { doses) }\end{array}$ & $\begin{array}{l}\text { Best ORR by } \\
\text { irRC } \\
\text { A } 53 \% \\
\text { B } 49 \% \\
\text { C } 71 \%\end{array}$ & $\begin{array}{l}\text { irRC } \\
\text { A } 5.3 \\
\text { B } 5.7 \\
\text { C } 6.4 \\
\text { Modified WHO } \\
\text { A } 5.2 \\
\text { B } 3.9 \\
\text { C } 5.2\end{array}$ & $\begin{array}{l}\text { A } 10.5^{\mathrm{a}} \\
\text { B } 9.1^{\mathrm{a}} \\
\text { C } 12.5^{\mathrm{a}}\end{array}$ & $\begin{array}{l}\text { (Immune- } \\
\text { related) } \\
\text { A } 9 \% \\
\text { B } 21 \% \\
\text { C } 17 \%\end{array}$ \\
\hline $\begin{array}{l}\text { Weber } \\
\text { et } \mathrm{al}^{72}\end{array}$ & 59 & $\begin{array}{l}\text { First-line, } \\
\text { advanced } \\
\text { melanoma }\end{array}$ & $\begin{array}{l}\text { A Ipi I0 mg/kg q3w } \leq 4 \text { doses } \\
\text { B Ipi } \leq 4 \text { doses }+ \text { Dac } \\
850 \mathrm{mg} / \mathrm{m}^{2} \text { q3w } \\
\text { C Ipi } \leq 4 \text { doses + Pac } \\
\quad 175 \mathrm{mg} / \mathrm{m}^{2}+\text { Carbo AUC } 6\end{array}$ & $\begin{array}{l}\text { Immune-related } \\
\text { A } 33 \% \\
\text { B } 33 \% \\
\text { C } 28 \% \\
\text { Modified WHO } \\
\text { A } 29 \% \\
\text { B } 28 \% \\
\text { C } 11 \%\end{array}$ & NR & NR & $\begin{array}{l}\text { (Treatment- } \\
\text { related) } \\
\text { A } 50 \% \\
\text { B } 74 \% \\
\text { C } 75 \%\end{array}$ \\
\hline $\begin{array}{l}\text { Antonia } \\
\text { et } \mathrm{al}^{75}\end{array}$ & 56 & $\begin{array}{l}\text { First-line, } \\
\text { advanced NSCLC }\end{array}$ & $\begin{array}{l}\text { A Nivo } 10 \mathrm{mg} / \mathrm{kg} \text { q3w }+ \text { Gem } \\
\text { I,250 mg/m² + Cis } 75 \mathrm{mg} / \mathrm{m}^{2} \\
\text { (squamous, } \mathrm{n}=\mathrm{I} \text { ) } \\
\text { B Nivo } 10 \mathrm{mg} / \mathrm{kg}+\text { Pem } \\
500 \mathrm{mg} / \mathrm{m}^{2}+\text { Cis } 75 \mathrm{mg} / \mathrm{m}^{2} \\
\text { (nonsquamous, } \mathrm{n}=15 \text { ) } \\
\text { C Nivo } 10 \mathrm{mg} / \mathrm{kg}+\text { Pac } \\
200 \mathrm{mg} / \mathrm{m}^{2}+\text { Carbo AUC } 6 \\
\text { q3w (squamous and } \\
\text { nonsquamous, } \mathrm{n}=15 \text { ) } \\
\text { D Nivo } 5 \mathrm{mg} / \mathrm{kg}+\text { Pac } \\
200 \mathrm{mg} / \mathrm{m}^{2}+\text { Carbo AUC } 6 \\
\text { q3w (squamous and } \\
\text { nonsquamous, } \mathrm{n}=14 \text { ) }\end{array}$ & $\begin{array}{l}\text { RECIST } \\
\text { A } 33 \% \\
\text { B } 47 \% \\
\text { C } 47 \% \\
\text { D } 43 \%\end{array}$ & $\begin{array}{l}\text { A } 5.7 \\
\text { B } 6.8 \\
\text { C } 4.8 \\
\text { D } 7.1\end{array}$ & $\begin{array}{l}\text { A } 11.6 \\
\text { B } 19.2 \\
\text { C } 14.9 \\
\text { D Not } \\
\text { reached }\end{array}$ & $\begin{array}{l}\text { Total } \leq 7 \% \\
\text { (Treatment- } \\
\text { related) } \\
\text { Pneumonitis } \\
\text { ( } n=4) \text {, fatigue, } \\
\text { and acute renal } \\
\text { failure (grade } 3 \\
\text { only; } n=3 \text { each) }\end{array}$ \\
\hline $\begin{array}{l}\text { Jamal } \\
\text { et al }{ }^{73,74}\end{array}$ & 30 & $\begin{array}{l}\text { Unresectable, } \\
\text { advanced } \\
\text { melanoma }\end{array}$ & $\begin{array}{l}\text { A Ipi } 3 \mathrm{mg} / \mathrm{kg} \text { q3w } 4 \text { doses starting } \\
\text { at week } 4 \text { (concurrent) + Pac } \\
\text { I75 mg/m² + Carbo AUC } 6 \\
\text { q3w } 5 \text { doses } \\
\text { B Ipi } 3 \mathrm{mg} / \mathrm{kg} \text { q3w } 4 \text { doses } \\
\text { (I-week delay) + Pac } \\
\text { I } 75 \mathrm{mg} / \mathrm{m}^{2}+\text { Carbo AUC } 6 \\
\text { q3w } 5 \text { doses }\end{array}$ & $\begin{array}{l}26.7 \text { (by irRC) } \\
\text { for all patients }\end{array}$ & NR & $\begin{array}{l}\text { I5.9 for all } \\
\text { patients }\end{array}$ & Total 63\% \\
\hline $\begin{array}{l}\text { Horinouchi } \\
\text { et } \mathrm{al}^{70}\end{array}$ & 15 & $\begin{array}{l}\text { First-line, } \\
\text { stage IIIB/IV } \\
\text { or recurrent } \\
\text { NSCLC } \\
\text { (Japanese) }\end{array}$ & $\begin{array}{l}\text { A Phased lpi } 3 \mathrm{mg} / \mathrm{kg}+\mathrm{Pac} \\
\text { I75 mg/m² }+ \text { Carbo } \\
\text { AUC } 6 \mathrm{q} 3 \mathrm{w} \\
\text { B Phased lpi } 10 \mathrm{mg} / \mathrm{kg}+\mathrm{Pac} \\
175 \mathrm{mg} / \mathrm{m}^{2}+\text { Carbo } \\
\text { AUC } 6 \mathrm{q} 3 \mathrm{w}\end{array}$ & $\begin{array}{l}\text { RECIST } \\
\text { A } 3 / 6 \\
\text { B } 3 / 7\end{array}$ & NR & NR & $\begin{array}{l}\text { Neutropenia } \\
\text { (100\% vs } 100 \%), \\
\text { leukopenia ( } 50 \% \\
\text { vs } 17 \%) \text {, anemia } \\
\text { (0\% vs } 66.7 \%)\end{array}$ \\
\hline
\end{tabular}


Table 2 (Continued)

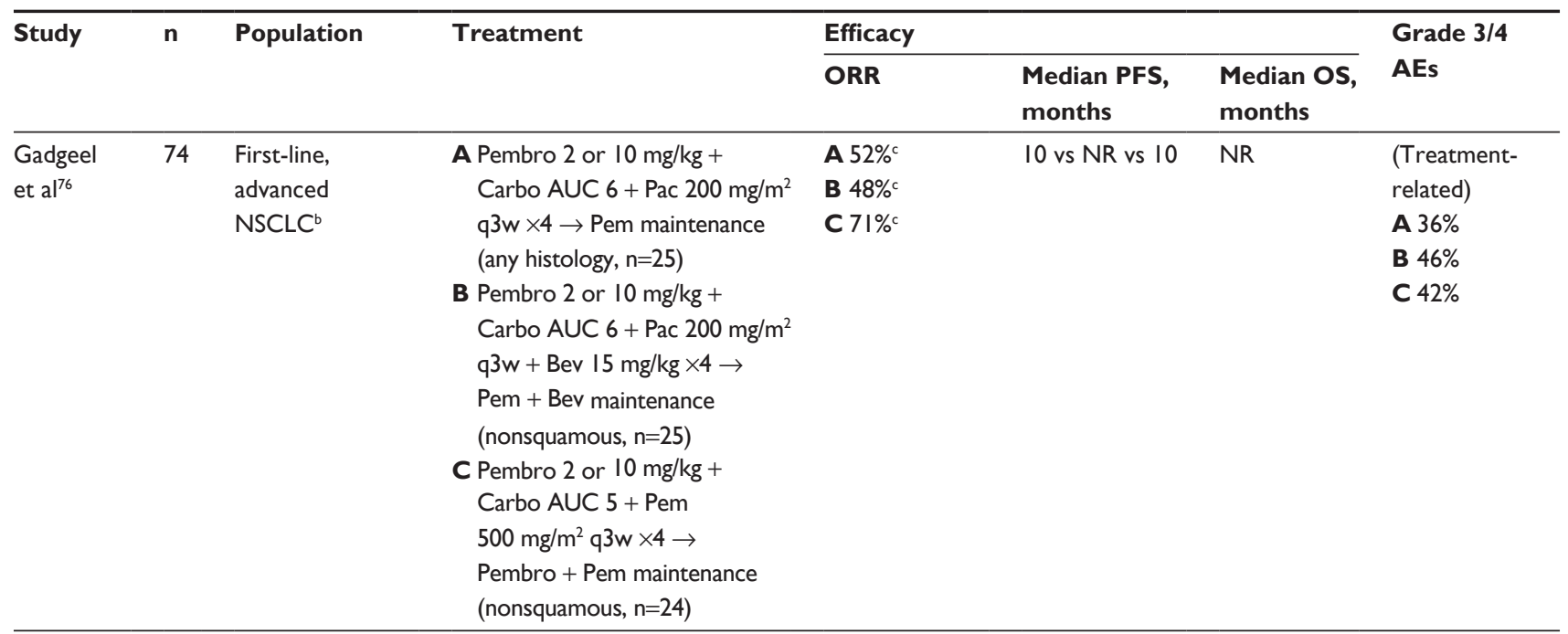

Notes: aData based on a follow-up OS analysis; 'bithout EGFR-sensitizing mutation or ALK translocation only; 'confirmed.

Abbreviations: AEs, adverse events; AUC, area under the curve; Bev, bevacizumab; Carbo, carboplatin; Cis, cisplatin; Dac, dacarbazine; Gem, gemcitabine; Ipi, ipilimumab; irRC, immune-related response criteria; Nivo, nivolumab; NR, not reported; NSCLC, non-small-cell lung cancer; Pac, paclitaxel; Pem, pemetrexed; Pembro, pembrolizumab; PFS, progression-free survival; q3w, every 3 weeks; RECIST, Response Evaluation Criteria In Solid Tumors; ORR, overall response rate; OS, overall survival; WHO, World Health Organization.

The phased ipilimumab regimen led to improved median PFS by immune-related response criteria (irRC; primary end point) versus the control paclitaxel/carboplatin regimen (5.7 vs 4.6 months, HR $0.72 ; P=0.05$ ). The median OS of the phased ipilimumab regimen was nearly 4 months longer compared with the control paclitaxel/carboplatin regimen, but the difference was not significant (12.2 vs 8.3 months, HR $0.87 ; P=0.23$ ). Median PFS and OS were 5.5 and 9.7 months, respectively, for the concurrent ipilimumab regimen, but were also not significantly different from those for the control paclitaxel/carboplatin regimen. In a subset analysis, patients with squamous NSCLC derived a greater benefit from phased ipilimumab than did patients with nonsquamous NSCLC. The incidence of treatment-related grade 3 or 4 adverse events was similar across the three regimens $(37 \%$ for the control paclitaxel/carboplatin arm, 39\% for phased ipilimumab, and $41 \%$ for concurrent ipilimumab), with a greater incidence of immune-related grade 3 or 4 adverse events in the ipilimumab arms (6\% for paclitaxel/carboplatin, 15\% for phased ipilimumab, and $20 \%$ for concurrent ipilimumab). Importantly, the incidence of adverse events typically associated with paclitaxel/carboplatin (fatigue, neuropathy, and neutropenia) was not increased with the addition of ipilimumab.

In a Phase I dose-escalation study in Japanese patients with advanced NSCLC, phased ipilimumab (3 or $10 \mathrm{mg} / \mathrm{kg}$ q3w) in combination with paclitaxel/carboplatin also demonstrated antitumor activity and a consistent safety profile. ${ }^{70}$ Additionally, a Phase II trial using the phased and concurrent doses/schedules of ipilimumab (10 mg/kg q3w) plus paclitaxel/carboplatin was conducted in chemotherapy-naïve patients with extensive-disease SCLC. ${ }^{71}$ Again, phased ipilimumab, but not concurrent ipilimumab, improved median PFS (by irRC) compared with the control paclitaxel/carboplatin regimen (6.4 vs 5.3 months, HR 0.64; $P=0.03$ ). Median OS was $10.5,12.5$, and 9.1 months for the control paclitaxel/ carboplatin, phased ipilimumab, and concurrent ipilimumab regimens, respectively. Safety results were similar to those noted for the NSCLC trial previously described here.

Taken together, these trials indicate that giving chemotherapy before immunotherapy leads to better outcomes, which may be explained by the "priming effect" that chemotherapy has on the immune system. Another study demonstrated that ipilimumab could be safely combined with dacarbazine or paclitaxel/carboplatin in patients with previously untreated advanced melanoma, but the initial efficacy results of this Phase I trial indicated that the combination of ipilimumab (10 mg/kg q3w) plus paclitaxel/carboplatin did not lead to better outcomes compared with ipilimumab alone or ipilimumab plus dacarbazine. ${ }^{72}$ In a Phase II study evaluating concurrent or sequential ipilimumab ( $3 \mathrm{mg} / \mathrm{kg} \mathrm{q} 3 \mathrm{w})$ in combination with paclitaxel/carboplatin in patients with advanced melanoma, no differences in outcomes were observed between the regimens, with a best overall response rate (ORR) of $26.7 \%$, a disease-control rate of $56.7 \%$ (by irRC), and a median OS of 15.9 months in all patients. Grade 3/4 adverse events were observed in $63 \%$ of patients. ${ }^{73,74}$ 
With regard to the PD1/PDL1 inhibitors, early results of two NSCLC trials demonstrated antitumor activity of a PD1 inhibitor combined with paclitaxel-based therapy (Table 2). ${ }^{75,76}$ In a Phase I trial, patients with chemotherapy-naïve NSCLC were assigned to one of four treatment cohorts according to histology: nivolumab (10 mg/kg q3w) plus gemcitabine/ cisplatin (squamous, $\mathrm{n}=12$ ), nivolumab $(10 \mathrm{mg} / \mathrm{kg}$ q3w) plus pemetrexed/cisplatin (nonsquamous, $\mathrm{n}=15$ ), nivolumab $(10 \mathrm{mg} / \mathrm{kg} \mathrm{q} 3 \mathrm{w}$ ) plus paclitaxel/carboplatin (any histology, $\mathrm{n}=15)$, or nivolumab ( $5 \mathrm{mg} / \mathrm{kg} \mathrm{q} 3 \mathrm{w})$ plus paclitaxel/ carboplatin (any histology, $\mathrm{n}=14$ ). ${ }^{75}$ In 56 evaluable patients, ORRs by Response Evaluation Criteria in Solid Tumors were $33 \%, 47 \%, 47 \%$, and $43 \%$, and median OS was $11.6,19.2$, and 14.9 months, and not reached, respectively. The overall incidence of select grade 3 or 4 adverse events was $\leq 7 \%$. In the Phase I/II KEYNOTE-021 trial, the combination of pembrolizumab (2 or $10 \mathrm{mg} / \mathrm{kg} \mathrm{q3w}$ ) plus paclitaxel/carboplatin for four cycles followed by pembrolizumab maintenance demonstrated an ORR of $52 \%$ in chemotherapy-naïve patients with advanced NSCLC. ${ }^{76}$ The incidence of grade 3 or 4 adverse events was $36 \%$ with this combination regimen.

Nanoparticle albumin-bound paclitaxel ( $n a b$-paclitaxel) is a form of paclitaxel that, unlike conventional paclitaxel, is formulated without the use of a solvent and does not require steroid premedication to prevent hypersensitivity reactions. ${ }^{55,57}$ In pharmacokinetic and preclinical studies, $n a b$-paclitaxel displayed properties related to its distinct formulation compared with standard paclitaxel, which is formulated with Kolliphor EL (formerly known as Cremophor EL). In these studies, nab-paclitaxel demonstrated tenfold higher mean maximum concentration of free paclitaxel in the plasma of patients with advanced solid tumors, ${ }^{77}$ delivery of $33 \%$ higher drug concentration to tumors in preclinical xenograft models, ${ }^{78}$ enhanced transport across endothelial cell monolayers, ${ }^{78}$ and faster and greater tissue penetration and slower elimination of paclitaxel in patients' tissues, including tumors. ${ }^{79}$ Currently, nab-paclitaxel is indicated for the treatment of metastatic breast cancer, advanced NSCLC (in combination with carboplatin), and metastatic pancreatic cancer (in combination with gemcitabine), based on achieving statistical significance for the primary end point in Phase III trials versus a standard-chemotherapy regimen..$^{55,80-82}$

Current reports of $n a b$-paclitaxel with checkpoint inhibitors are limited, but early data suggest that $n a b$-paclitaxel-based therapy may augment the antitumor activity of these agents. In a preliminary analysis of a Phase IB trial of patients with various solid tumors, a cohort of 16 efficacy-evaluable patients with advanced NSCLC treated with the combination of atezolizumab $(15 \mathrm{mg} / \mathrm{kg} \mathrm{q} 3 \mathrm{w})$ plus nab-paclitaxel $\left(100 \mathrm{mg} / \mathrm{m}^{2}\right.$ weekly) plus carboplatin achieved an ORR of $56 \%$ and a complete response rate of $25 \% .^{83,84}$ Two other trial arms of atezolizumab plus either paclitaxel/ carboplatin (efficacy evaluable, $\mathrm{n}=8$ ) or pemetrexed/ carboplatin (efficacy evaluable, $\mathrm{n}=17$ ) also demonstrated favorable ORRs of $50 \%$ and $76 \%$, respectively, but no patients receiving the paclitaxel- or pemetrexed-containing regimens have achieved a complete response to date. The most common grade 3 or 4 adverse event was neutropenia (35\% in the $n a b$-paclitaxel arm, 29\% in the paclitaxel arm, and $25 \%$ in the pemetrexed arm). Initial analysis of a cohort of patients with triple-negative breast cancer treated with atezolizumab (800 mg q2w) plus nab-paclitaxel $\left(125 \mathrm{mg} / \mathrm{m}^{2}\right.$ weekly for first 3 of 4 weeks) within the same Phase IB trial demonstrated a best ORR of $71 \%$ ( $42 \%$ confirmed) in 24 patients evaluable for efficacy. ${ }^{85}$ Patients with metastatic triple-negative breast cancer who received the atezolizumab plus nab-paclitaxel regimen as first-line therapy derived the greatest benefit (best ORR, $46 \%$ confirmed). A total of 32 patients with triple-negative breast cancer were evaluable for safety. Neutropenia and decreased neutrophil count were the most common grade $3 / 4 \mathrm{AE}$, occurring in $47 \%$ of patients receiving atezolizumab plus $n a b$-paclitaxel. The investigators also found that expression of PDL1 was mostly restricted to immune cells in excised tumors, but the level of expression did not appear to correlate with response. Based on the positive results of this Phase IB trial, the combination of atezolizumab and $n a b$-paclitaxel is being evaluated in Phase III trials in triple-negative breast cancer and NSCLC (Figure 1). ${ }^{86}$

Early clinical trials have indicated that pancreatic tumors may be fully resistant to monotherapy with immunecheckpoint inhibitors..$^{44,45,87}$ However, recent data from a mouse-model study demonstrated that this resistance could be overcome with a combination therapy that contained nab-paclitaxel. ${ }^{43}$ Treatment with a combination of a CD40 antibody, nab-paclitaxel, gemcitabine, a PD1 antibody, and a CTLA4 antibody led to complete tumor rejection and longterm tumor-free survival in treated mice. ${ }^{43} n a b$-Paclitaxel is currently being studied in combination with nivolumab or pembrolizumab in pancreatic cancer (Table 3), as well as with other checkpoint inhibitors (atezolizumab, durvalumab, and ipilimumab) in multiple trials of solid tumors. ${ }^{86}$

\section{Conclusion}

Tumor-mediated immune suppression and aberrant tumor microenvironments that promote tumor growth and 
A IMpower 130

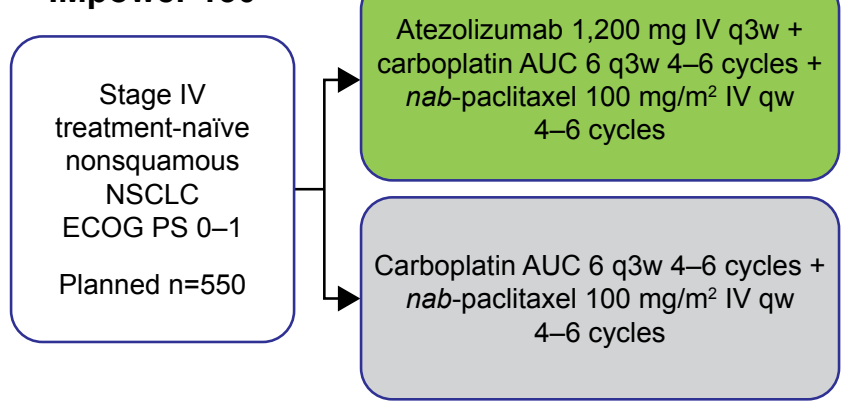

B IMpower 131

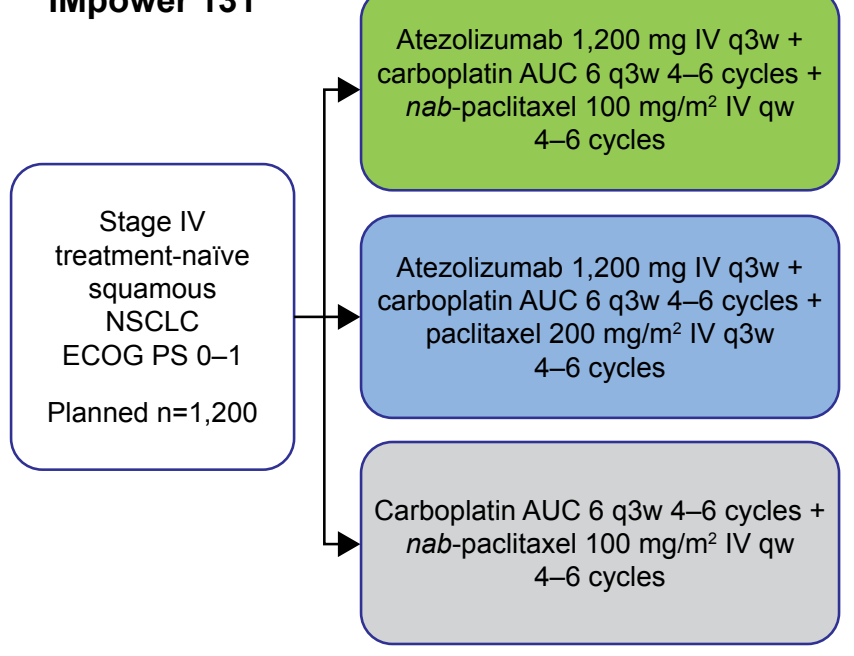

\section{IMpassion 130}

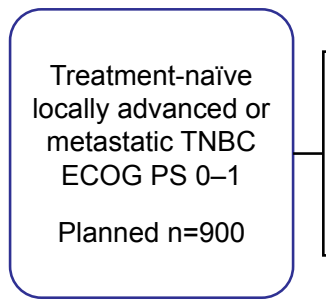

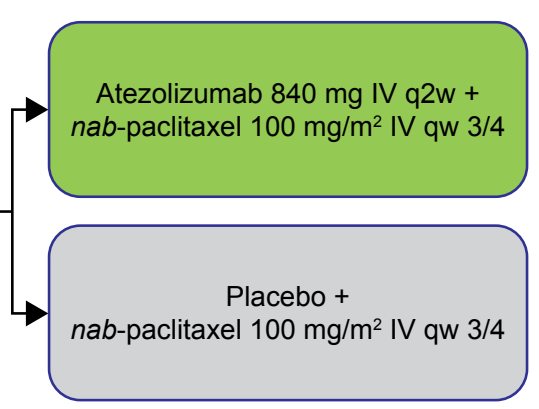

\section{End points}

- Primary: PFS by investigator ${ }^{a}$

- Secondary: ORRa ${ }^{\mathrm{a}}$, OS, DOR,

PFS by independent reviewa,

QOL, and safety

\section{Regions}

- Europe

- North America

ClinicalTrials.gov \#NCT02367781

\section{End points}

- Primary: PFS by investigator ${ }^{a}$

- Secondary: OS, QOL, ORR ${ }^{a}$, DOR,

PFS by independent review ${ }^{a}$

Regions

- Asia

- Australia

- Europe

- North America

- South America

ClinicalTrials.gov \#NCT02367794

Figure I Study schematics of ongoing Phase III trials of atezolizumab in combination with nab-paclitaxel chemotherapy in NSCLC (A, IMpower I30 and B, IMpower I3I) and TNBC (C, IMpassion 130). ${ }^{86}$

Note: a Using RECIST criteria.

Abbreviations: AUC, area under the curve; DOR, duration of response; ECOG, Eastern Cooperative Oncology Group; IM, intramuscular; IV, intravenous; NSCLC, non-small-cell lung cancer; ORR, overall response rate; OS, overall survival; PFS, progression-free survival; PS, performance status; QOL, quality of life; RECIST, Response Evaluation Criteria In Solid Tumors; TNBC, triple-negative breast cancer; qw, every week; qw 3/4, first 3 of every 4 weeks; q2w, every 2 weeks.

metastasis are just two of the many challenges to achieving an optimal and sustained treatment response in patients with cancer, especially those with metastatic disease. Chemotherapy agents in general owe part of their antitumor activity to positive changes in the host immune system, such as providing a natural vaccine, recruiting immune cells to the tumor microenvironment, and suppressing regulatory T cells. However, as monotherapy, the ability of chemotherapy to restore antitumor immunity completely is limited. Likewise, immunotherapy agents alone are not always able to fully elicit an attack on tumor cells. Therefore, combinations of chemotherapy and immunotherapy may have mutual benefits. Understanding how a particular chemotherapy agent modulates the immune system will be important to help decide the best immunotherapy-chemotherapy combinations and to maximize therapeutic benefit. However, such a vast array of potential combinations of chemotherapy and immunotherapy agents calls for a cooperative effort to evaluate the various combinations systematically. This is especially true with the limitations in existing preclinical 
Table 3 Clinical development of checkpoint inhibitors + nab-paclitaxel-based chemotherapy in solid tumors ${ }^{86}$

\begin{tabular}{|c|c|c|c|c|}
\hline & Checkpoint inhibitor & Disease/setting & Phase & ClinicalTrials.gov identifier \\
\hline \multirow[t]{13}{*}{ PDI } & Nivolumab & NSCLC & $\mathrm{I}$ & NCT02309I77 \\
\hline & & $\mathrm{MBC}$ & & \\
\hline & & Metastatic PC & & \\
\hline & & Advanced NSCLC & $\mathrm{I} / \mathrm{II}$ & NCT02574078 \\
\hline & Pembrolizumab & Neoadjuvant TNBC & 1 & NCT02622074 \\
\hline & & Advanced NSCLC & I & NCT0I840579 \\
\hline & & Advanced NSCLC & $\mathrm{I} / \mathrm{II}$ & NCT02382406 \\
\hline & & & & NCT02733250 \\
\hline & & Metastatic solid tumors & $\mathrm{I} / \mathrm{II}$ & NCT0233I25I \\
\hline & & Advanced NSCLC & II & NCT0268446I \\
\hline & & HER2- MBC & II & NCT02752685 \\
\hline & & Locally recurrent or metastatic TNBC & III & NCT02819518 \\
\hline & & Metastatic squamous NSCLC & III & NCT02775435 \\
\hline \multirow[t]{9}{*}{ PDLI } & Atezolizumab & Solid tumors including metastatic PC & I & NCT027I553I \\
\hline & & Neoadjuvant NSCLC & II & NCT027I 6038 \\
\hline & & Metastatic nonsquamous NSCLC & III & NCT0236778I \\
\hline & & Metastatic squamous NSCLC & III & NCT02367794 \\
\hline & & Neoadjuvant TNBC & II & NCT02530489 \\
\hline & & Metastatic TNBC & III & NCT0242589I \\
\hline & Durvalumab & Neoadjuvant TNBC & $\mathrm{I} / \mathrm{II}$ & NCT02489448 \\
\hline & & & II & NCT02685059 \\
\hline & & Advanced solid tumors & 1 & NCT026582।4 \\
\hline CTLA4 & Ipilimumab & Metastatic melanoma & II & NCT0I827III \\
\hline
\end{tabular}

Abbreviations: MBC, metastatic breast cancer; NSCLC, non-small-cell lung cancer; PC, pancreatic cancer; TNBC, triple-negative breast cancer.

models in recapitulating all the complex interactions between the immune system and tumors in a human host. To this end, the Cancer MoonShot 2020 Quantitative Integrative Lifelong Trial program is an ongoing effort to bring together all involved parties to assess various combinations of immunotherapy and chemotherapy agents in a collaborative manner. ${ }^{88}$ Indeed, studies are ongoing to determine optimal combinations and schedules of chemotherapy and emerging immunotherapy agents.

Trials are ongoing to determine whether $n a b$-paclitaxel would be an ideal chemotherapy candidate for various immunotherapy combination approaches in solid tumors. $n a b$-Paclitaxel does not appear to have overlapping toxicities with checkpoint inhibitors or to worsen immune-related toxicities. ${ }^{83-85}$ Correlative studies looking at the effects of pharmacokinetics, dosing schedules, drug formulations, and concomitant supportive medications will be important in identifying the ideal immunotherapy combination strategy for $n a b$-paclitaxel. Clinical study results of $n a b$ paclitaxel in combination with checkpoint inhibitors are eagerly awaited.

\section{Acknowledgment}

Writing assistance was provided by Kerry Garza, PhD, MediTech Media, through funding by Celgene Corporation.

\section{Disclosure}

HHS has served as a scientific advisor and principal investigator for Celgene. The author reports no other conflicts of interest in this work.

\section{References}

1. Finn OJ. Cancer immunology. N Engl J Med. 2008;358:2704-2715.

2. Ahmad M, Rees RC, Ali SA. Escape from immunotherapy: possible mechanisms that influence tumor regression/progression. Cancer Immunol Immunother. 2004;53:844-854.

3. Chen DS, Mellman I. Oncology meets immunology: the cancerimmunity cycle. Immunity. 2013;39:1-10.

4. Disis ML. Immune regulation of cancer. J Clin Oncol. 2010;28: 4531-4538.

5. Gajewski TF, Schreiber H, Fu YX. Innate and adaptive immune cells in the tumor microenvironment. Nat Immunol. 2013;14:1014-1022.

6. Mellman I, Coukos G, Dranoff G. Cancer immunotherapy comes of age. Nature. 2011;480:480-489.

7. Blank C, Mackensen A. Contribution of the PD-L1/PD-1 pathway to T-cell exhaustion: an update on implications for chronic infections and tumor evasion. Cancer Immunol Immunother. 2007;56:739-745.

8. Allard B, Turcotte M, Stagg J. CD73-generated adenosine: orchestrating the tumor-stroma interplay to promote cancer growth. J Biomed Biotechnol. 2012;2012:485156.

9. Galon J, Costes A, Sanchez-Cabo F, et al. Type, density, and location of immune cells within human colorectal tumors predict clinical outcome. Science. 2006;313:1960-1964.

10. Kreike B, van Kouwenhove M, Horlings H, et al. Gene expression profiling and histopathological characterization of triple-negative/ basal-like breast carcinomas. Breast Cancer Res. 2007;9:R65.

11. Dieu-Nosjean MC, Antoine M, Danel C, et al. Long-term survival for patients with non-small-cell lung cancer with intratumoral lymphoid structures. J Clin Oncol. 2008;26:4410-4417. 
12. Zhang L, Conejo-Garcia JR, Katsaros D, et al. Intratumoral T cells, recurrence, and survival in epithelial ovarian cancer. $N$ Engl J Med. 2003;348:203-213.

13. Ene-Obong A, Clear AJ, Watt J, et al. Activated pancreatic stellate cells sequester CD8+ T cells to reduce their infiltration of the juxtatumoral compartment of pancreatic ductal adenocarcinoma. Gastroenterology. 2013;145:1121-1132.

14. Mahmoud SM, Paish EC, Powe DG, et al. Tumor-infiltrating CD8+ lymphocytes predict clinical outcome in breast cancer. J Clin Oncol. 2011;29:1949-1955.

15. Curiel TJ, Coukos G, Zou L, et al. Specific recruitment of regulatory $\mathrm{T}$ cells in ovarian carcinoma fosters immune privilege and predicts reduced survival. Nat Med. 2004;10:942-949.

16. Gobert M, Treilleux I, Bendriss-Vermare N, et al. Regulatory T cells recruited through CCL22/CCR4 are selectively activated in lymphoid infiltrates surrounding primary breast tumors and lead to an adverse clinical outcome. Cancer Res. 2009;69:2000-2009.

17. Hasegawa T, Suzuki H, Yamaura T, et al. Prognostic value of peripheral and local forkhead box $\mathrm{P} 3$ regulatory $\mathrm{T}$ cells in patients with non-smallcell lung cancer. Mol Clin Oncol. 2014;2:685-694.

18. Tang Y, Xu X, Guo S, et al. An increased abundance of tumor-infiltrating regulatory $\mathrm{T}$ cells is correlated with the progression and prognosis of pancreatic ductal adenocarcinoma. PLoS One. 2014;9:e91551.

19. Ribas A. Tumor immunotherapy directed at PD-1. N Engl J Med. 2012; 366:2517-2519.

20. McDermott DF, Atkins MB. PD-1 as a potential target in cancer therapy. Cancer Med. 2013;2:662-673.

21. Opdivo (nivolumab) injection, for intravenous use [package insert]. New York: Bristol-Myers Squibb; 2016

22. Yervoy (ipilimumab) injection, for intravenous use [package insert]. New York: Bristol-Myers Squibb; 2015.

23. Keytruda (pembrolizumab) for injection, for intravenous use [package insert]. Whitehouse Station, NJ: Merck \& Co Inc; 2016.

24. Tecentriq (atezolizumab) injection, for intravenous use [package insert]. Basel: Hoffman-La Roche Ltd; 2016.

25. Yervoy (ipilimumab) [summary of product characteristics]. New York: Bristol-Myers Squibb; 2015.

26. Keytruda (pembrolizumab) [summary of product characteristics]. Whitehouse Station, NJ: Merck \& Co Inc; 2016.

27. AstraZeneca. Durvalumab granted breakthrough therapy designation by US FDA for treatment of patients with PD-L1 positive urothelial bladder cancer [press release]. London: AstraZeneca; 2016 [February 17]. Available from: https://www.astrazeneca.com/ media-centre/press-releases/2016/Durvalumab-granted-BreakthroughTherapy-designation-by-US-FDA-for-treatment-of-patients-withPD-L1-positive-urothelial-bladder-cancer-17022016.html. Accessed March 8, 2016.

28. Hodi FS, O'Day SJ, McDermott DF, et al. Improved survival with ipilimumab in patients with metastatic melanoma. $N$ Engl J Med. 2010;363:711-723.

29. Robert C, Long GV, Brady B, et al. Nivolumab in previously untreated melanoma without BRAF mutation. $N$ Engl J Med. 2015;372: $320-330$.

30. Robert C, Schachter J, Long GV, et al. Pembrolizumab versus ipilimumab in advanced melanoma. N Engl J Med. 2015;372:2521-2532.

31. Ribas A, Puzanov I, Dummer R, et al. Pembrolizumab versus investigator-choice chemotherapy for ipilimumab-refractory melanoma (KEYNOTE-002): a randomised, controlled, phase 2 trial. Lancet Oncol. 2015;16:908-918.

32. Opdivo (nivolumab). Tokyo: Ono Pharmaceutical Co Ltd; 2014.

33. Opdivo (nivolumab) [summary of product characteristics]. New York: Bristol-Myers Squibb; 2016.

34. Larkin J, Hodi FS, Wolchok JD. Combined nivolumab and ipilimumab or monotherapy in untreated melanoma. N Engl J Med. 2015; 373:1270-1271.
35. Borghaei H, Paz-Ares L, Horn L, et al. Nivolumab versus docetaxel in advanced nonsquamous non-small-cell lung cancer. $N$ Engl J Med. 2015;373:1627-1639.

36. Brahmer J, Reckamp KL, Baas P, et al. Nivolumab versus docetaxel in advanced squamous-cell non-small-cell lung cancer. $N$ Engl J Med. 2015;373:123-135.

37. Hamanishi J, Mandai M, Ikeda T, et al. Durable tumor remission in patients with platinum-resistant ovarian cancer receiving nivolumab. J Clin Oncol. 2015;33:5570.

38. Le DT, Bendell JC, Calvo E, et al. Safety and activity of nivolumab monotherapy in advanced and metastatic $(\mathrm{A} / \mathrm{M})$ gastric or gastroesophageal junction cancer (GC/GEC): results from the CheckMate-032 study. J Clin Oncol. 2016;34:6.

39. Plimack ER, Hammers HJ, Rini BI, et al. Updated survival results from a randomized, dose-ranging phase II study of nivolumab (NIVO) in metastatic renal cell carcinoma (mRCC). J Clin Oncol. 2015;33:4553.

40. Motzer RJ, Escudier B, McDermott DF, et al. Nivolumab versus everolimus in advanced renal-cell carcinoma. $N$ Engl J Med. 2015; 373:1803-1813.

41. Herbst RS, Baas P, Kim DW, et al. Pembrolizumab versus docetaxel for previously treated, PD-L1-positive, advanced non-small-cell lung cancer (KEYNOTE-010): a randomised controlled trial. Lancet. 2016; $387: 1540-1550$.

42. Lutzky J, Antonia SJ, Blake-Haskins A, et al. A phase 1 study of MEDI4736, an anti-PD-L1 antibody, in patients with advanced solid tumors. J Clin Oncol. 2014;32:3001.

43. Winograd R, Byrne KT, Evans RA, et al. Induction of T-cell immunity overcomes complete resistance to PD-1 and CTLA-4 blockade and improves survival in pancreatic carcinoma. Cancer Immunol Res. 2015; 3:399-411.

44. Royal RE, Levy C, Turner K, et al. Phase 2 trial of single agent ipilimumab (anti-CTLA-4) for locally advanced or metastatic pancreatic adenocarcinoma. J Immunother. 2010;33:828-833.

45. Brahmer JR, Tykodi SS, Chow LQ, et al. Safety and activity of antiPD-L1 antibody in patients with advanced cancer. $N$ Engl J Med. 2012;366:2455-2465.

46. Zitvogel L, Galluzzi L, Smyth MJ, Kroemer G. Mechanism of action of conventional and targeted anticancer therapies: reinstating immunosurveillance. Immunity. 2013;39:74-88.

47. Kaufman HL, Kirkwood JM, Hodi FS, et al. The Society for Immunotherapy of Cancer consensus statement on tumour immunotherapy for the treatment of cutaneous melanoma. Nat Rev Clin Oncol. 2013;10: 588-598.

48. Bracci L, Schiavoni G, Sistigu A, Belardelli F. Immune-based mechanisms of cytotoxic chemotherapy: implications for the design of novel and rationale-based combined treatments against cancer. Cell Death Differ. 2014;21:15-25.

49. Fridman WH, Pages F, Sautes-Fridman C, Galon J. The immune contexture in human tumours: impact on clinical outcome. Nat Rev Cancer. 2012;12:298-306.

50. Emens LA, Reilly RT, Jaffee EM. Breast cancer vaccines: maximizing cancer treatment by tapping into host immunity. Endocr Relat Cancer. 2005;12:1-17.

51. Machiels JP, Reilly RT, Emens LA, et al. Cyclophosphamide, doxorubicin, and paclitaxel enhance the antitumor immune response of granulocyte/macrophage-colony stimulating factor-secreting wholecell vaccines in HER-2/neu tolerized mice. Cancer Res. 2001;61: 3689-3697.

52. Lutsiak ME, Semnani RT, De Pascalis R, Kashmiri SV, Schlom J, Sabzevari H. Inhibition of CD4(+)25+ T regulatory cell function implicated in enhanced immune response by low-dose cyclophosphamide. Blood. 2005;105:2862-2868.

53. Chang CL, Hsu YT, Wu CC, et al. Dose-dense chemotherapy improves mechanisms of antitumor immune response. Cancer Res. 2013; 73:119-127. 
54. Emens LA, Asquith JM, Leatherman JM, et al. Timed sequential treatment with cyclophosphamide, doxorubicin, and an allogeneic granulocyte-macrophage colony-stimulating factor-secreting breast tumor vaccine: a chemotherapy dose-ranging factorial study of safety and immune activation. J Clin Oncol. 2009;27:5911-5918.

55. Abraxane for injectable suspension (paclitaxel protein-bound particles for injectable suspension) (albumin-bound) [package insert]. Summit, NJ: Celgene Corporation; 2015.

56. Taxotere (docetaxel) [package insert]. Bridgewater, NJ: Sanofi; 2013.

57. Taxol (paclitaxel) [package insert]. New York: Bristol-Myers Squibb; 2011.

58. Chan OT, Yang LX. The immunological effects of taxanes. Cancer Immunol Immunother. 2000;49:181-185.

59. Demaria S, Volm MD, Shapiro RL, et al. Development of tumorinfiltrating lymphocytes in breast cancer after neoadjuvant paclitaxel chemotherapy. Clin Cancer Res. 2001;7:3025-3030.

60. Carson WE 3rd, Shapiro CL, Crespin TR, Thornton LM, Andersen BL. Cellular immunity in breast cancer patients completing taxane treatment Clin Cancer Res. 2004;10:3401-3409.

61. Denkert C, Loibl S, Noske A, et al. Tumor-associated lymphocytes as an independent predictor of response to neoadjuvant chemotherapy in breast cancer. J Clin Oncol. 2010;28:105-113.

62. Tsuda N, Chang DZ, Mine T, et al. Taxol increases the amount and $\mathrm{T}$ cell activating ability of self-immune stimulatory multimolecular complexes found in ovarian cancer cells. Cancer Res. 2007;67: 8378-8387.

63. Vicari AP, Luu R, Zhang N, et al. Paclitaxel reduces regulatory T cell numbers and inhibitory function and enhances the anti-tumor effects of the TLR9 agonist PF-3512676 in the mouse. Cancer Immunol Immunother. 2009;58:615-628.

64. Garnett CT, Schlom J, Hodge JW. Combination of docetaxel and recombinant vaccine enhances $\mathrm{T}$-cell responses and antitumor activity: effects of docetaxel on immune enhancement. Clin Cancer Res. 2008; 14:3536-3544.

65. Michels T, Shurin GV, Naiditch H, Sevko A, Umansky V, Shurin MR Paclitaxel promotes differentiation of myeloid-derived suppressor cells into dendritic cells in vitro in a TLR4-independent manner. J Immunotoxicol. 2012;9:292-300.

66. Tsavaris N, Kosmas C, Vadiaka M, Kanelopoulos P, Boulamatsis D. Immune changes in patients with advanced breast cancer undergoing chemotherapy with taxanes. Br J Cancer. 2002;87:21-27.

67. Sevko A, Michels T, Vrohlings M, et al. Anti-tumor effect of paclitaxel is mediated by inhibition of MDSCs and chronic inflammation in the spontaneous melanoma model. J Immunol. 2013;190: 2464-2471.

68. Mullins D, Martins RS, Burger CJ, Elgert KD. Tumor cell-derived TGF- $\beta$ and IL-10 dysregulate paclitaxel-induced macrophage activation. J Leukoc Biol. 2001;69:129-137.

69. Lynch TJ, Bondarenko I, Luft A, et al. Ipilimumab in combination with paclitaxel and carboplatin as first-line treatment in stage IIIB/IV non-small-cell lung cancer: results from a randomized, double-blind, multicenter phase II study. J Clin Oncol. 2012;30:2046-2054

70. Horinouchi H, Yamamoto N, Fujiwara Y, et al. Phase I study of ipilimumab in phased combination with paclitaxel and carboplatin in Japanese patients with non-small-cell lung cancer. Invest New Drugs. 2015;33:881-889.

71. Reck M, Bondarenko I, Luft A, et al. Ipilimumab in combination with paclitaxel and carboplatin as first-line therapy in extensive-diseasesmall-cell lung cancer: results from a randomized, double-blind, multicenter phase 2 trial. Ann Oncol. 2013;24:75-83.
72. Weber J, Hamid O, Amin A, et al. Randomized phase I pharmacokinetic study of ipilimumab with or without one of two different chemotherapy regimens in patients with untreated advanced melanoma. Cancer Immun. 2013;13:7.

73. Jamal R, Belanger K, Friedmann J, et al. Randomized phase II study of ipilimumab (IPI) with carboplatin and paclitaxel (CP) in patients with unresectable stage III or IV metastatic melanoma (MM). J Clin Oncol. 2014;32:9066.

74. Jamal R, L Kempen L, Thebault P, et al. One-year overall survival (OS) and biomarker correlates from a phase II study of ipilimumab (IPI) with carboplatin and paclitaxel (CP) in patients with unresectable stage III or IV metastatic melanoma (MM). J Clin Oncol. 2015;33:9062.

75. Antonia S, Brahmer J, Gettinger S, et al. Nivolumab (anti-PD-1; BMS-936558, ONO-4538) in combination with platinum-based doublet chemotherapy (PT-DC) in advanced non-small cell lung cancer (NSCLC). J Clin Oncol. 2014;32:8113.

76. Gadgeel S, Stevenson J, Langer C, et al. Pembrolizumab (pembro) plus chemotherapy as front-line therapy for advanced NSCLC: KEYNOTE021 cohorts A-C. J Clin Oncol. 2016;34:9016.

77. Gardner ER, Dahut WL, Scripture CD, et al. Randomized crossover pharmacokinetic study of solvent-based paclitaxel and nab-paclitaxel. Clin Cancer Res. 2008;14:4200-4205.

78. Desai N, Trieu V, Yao Z, et al. Increased antitumor activity, intratumor paclitaxel concentrations, and endothelial cell transport of cremophorfree, albumin-bound paclitaxel, ABI-007, compared with cremophorbased paclitaxel. Clin Cancer Res. 2006;12:1317-1324.

79. Chen N, Li Y, Ye Y, Palmisano M, Chopra R, Zhou S. Pharmacokinetics and pharmacodynamics of nab-paclitaxel in patients with solid tumors: disposition kinetics and pharmacology distinct from solvent-based paclitaxel. J Clin Pharmacol. 2014;54:1097-1107.

80. Gradishar WJ, Tjulandin S, Davidson N, et al. Phase III trial of nanoparticle albumin-bound paclitaxel compared with polyethylated castor oil-based paclitaxel in women with breast cancer. J Clin Oncol. 2005;23:7794-7803.

81. Socinski MA, Bondarenko I, Karaseva NA, et al. Weekly nab-paclitaxel in combination with carboplatin versus solvent-based paclitaxel plus carboplatin as first-line therapy in patients with advanced non-smallcell lung cancer: final results of a phase III trial. J Clin Oncol. 2012; 30:2055-2062.

82. Von Hoff DD, Ervin T, Arena FP, et al. Increased survival in pancreatic cancer with nab-paclitaxel plus gemcitabine. $N$ Engl J Med. 2013;369:1691-1703.

83. Camidge DR, Liu SV, Powderly J, et al. Atezolizumab (MPDL3280A) combined with platinum-based chemotherapy in non-small cell lung cancer (NSCLC): a phase IB safety and efficacy update. J Thorac Oncol. 2015;10:S176-S177.

84. Giaccone G, Camidge DR, Liu SV, et al. Safety, activity and biomarker of atezolizumab (MPDL3280A) with platinum-based chemotherapy (chemo) in non-small cell lung cancer (NSCLC): a phase IB study. Eur J Cancer. 2015;51:S107-S108.

85. Adams S, Diamond J, Hamilton E, et al. Phase IB trial of atezolizumab in combination with nab-paclitaxel in patients with metastatic triplenegative breast cancer (mTNBC). J Clin Oncol. 2016;34:1009.

86. ClinicalTrials.gov [website on the Internet]. Available from: http:// www.clinicaltrials.gov. Accessed January 21, 2016.

87. Le DT, Lutz E, Uram JN, et al. Evaluation of ipilimumab in combination with allogeneic pancreatic tumor cells transfected with a GM-CSF gene in previously treated pancreatic cancer. J Immunother. 2013;36:382-389.

88. National Immunotherapy Coalition. Cancer MoonShot 2020. Available from: http://www.cancermoonshot2020.org. Accessed April 4, 2016. 


\section{Publish your work in this journal}

OncoTargets and Therapy is an international, peer-reviewed, open access journal focusing on the pathological basis of all cancers, potential targets for therapy and treatment protocols employed to improve the management of cancer patients. The journal also focuses on the impact of management programs and new therapeutic agents and protocols on

patient perspectives such as quality of life, adherence and satisfaction. The manuscript management system is completely online and includes a very quick and fair peer-review system, which is all easy to use. Visit http://www.dovepress.com/testimonials.php to read real quotes from published authors.

Submit your manuscript here: http://www.dovepress.com/oncotargets-and-therapy-journal 